\title{
Coagulation disorders in subjects undergoing pump-driven veno-venous ECCO2-r for severe acute hypercapnic respiratory failure - a single center experience
}

\author{
U Harler ${ }^{*}$, GF Lehner, J Hasslacher, M Joannidis \\ From ESICM LIVES 2015 \\ Berlin, Germany. 3-7 October 2015
}

\section{Introduction}

Recent evidence suggests low-flow extracorporeal $\mathrm{CO} 2$ removal (ECCO2-R) systems as safe and promising adjunctive therapy to avoid endotracheal intubation and the related negative consequences in subjects with severe hypercapnic respiratory failure [1]. In high-flow extracorporeal membrane oxygenation systems heterogeneous coagulation disorders are a well-known complication. However, to date there is little evidence for the influence of pump-driven low-flow veno-venous $\mathrm{ECCO} 2-\mathrm{R}$ on the coagulation system.

\section{Objectives}

This study is a retrospective analysis of four subjects developing coagulation disorders with bleeding complications while undergoing ECCO2-R.

\section{Methods}

Four subjects treated with a pump-driven veno-venous ECCO2-R (system: iLA Activve ${ }^{\mathbb{R}}$; membrane ventilator: Minilung $^{\circledR}$; Novalung GmbH, Talheim, Germany) for severe hypercapnic respiratory failure due to acute exacerbation of COPD were included in this study. Unfractionated heparin was used for anticoagulation with a target aPTT of 45-55 sec. Coagulation parameters i.e. hemoglobin, platelets, fibrinogen, antithrombin and D-DIMER were retrieved from the charts at treatment initiation and during the time range starting 72 hours before and ending at the clinical onset of the bleeding complication.

\section{Results}

Mean application time of ECCO2-R was $196.5 \mathrm{~h} \mathrm{(} \pm$ 77.4 ) with an average blood flow of $1.1 \mathrm{l} / \mathrm{min}( \pm 0.2)$.

Table 1. Coagulation parameters

\begin{tabular}{llllll}
\hline & baseline* & $\mathbf{- 7 2 h}$ & $\mathbf{- 4 8 h}$ & $\mathbf{- 2 4 h}$ & day of bleeding \\
\hline hemoglobin (G/l) & $114.5( \pm 24.3)$ & $97.8( \pm 11.8)$ & $88.8( \pm 16.9)$ & $79( \pm 14.5)$ & $81.8( \pm 14.1)$ \\
\hline thrombocytes (G/l) & $195.5( \pm 125.5)$ & $193.3( \pm 136.0)$ & $171( \pm 122.5)$ & $141.8( \pm 122.1)$ & $125.5( \pm 100.2)$ \\
\hline fibrinogen $(\mathbf{m g} / \mathbf{d l})$ & $370( \pm 97.4)$ & $358.8( \pm 133.9)$ & $343.5( \pm 136.3)$ & $255.5( \pm 136.2)$ & $235.5( \pm 142.9)$ \\
\hline AT III (\%) & $101( \pm 20.9)$ & $86( \pm 25.7)$ & $80.5( \pm 21.6)$ & $69.5( \pm 23.7)$ & $74( \pm 14.5)$ \\
\hline D-DIMER $(\boldsymbol{\mu g} / \mathbf{l})$ & $1170( \pm 435.4)$ & $5079( \pm 6597)$ & $7569( \pm 11340)$ & $11048( \pm 16140)$ & $12709( \pm 15453)$ \\
\hline PT (\%) & $90.8( \pm 18.7)$ & $91( \pm 19.8)$ & $86.8( \pm 18.8)$ & $81.8( \pm 16.9)$ & $82.5( \pm 24.8)$ \\
\hline aPTT $(\mathbf{s e c})$ & $38.8( \pm 12.0)$ & $39.8( \pm 10.4)$ & $46.8( \pm 11.3)$ & $49.5( \pm 15.1)$ & $36.8( \pm 7.7)$ \\
\hline Heparin (IU/kg/day) & 0 & $207.8( \pm 80.5)$ & $259.7( \pm 84.3)$ & $150.1( \pm 115.7)$ & $78.33( \pm 97.1)$ \\
\hline
\end{tabular}

Results are presented as mean ( $\pm \mathrm{SD}$ ).

*baseline refers to the last value before application of ECCO2-R 
Bleeding events consisted of two pulmonary bleedings, one large soft tissue hematoma and one hemothorax. Coagulation parameters are depicted below in Table 1. ECCO2-R was removed in all subjects after onset of the bleeding complication resulting in stabilization of the coagulation state.

\section{Conclusions}

Despite adequate anticoagulation subjects undergoing pump-driven veno-venous ECCO2-R developed coagulation disorders similar to disseminated intravascular coagulation with concomitant bleeding complications. The underlying mechanism remains to be clarified.

Published: 1 October 2015

\section{Reference}

1. Kluge S, Braune SA, Engel M, Nierhaus A, Frings D, Ebelt $H$, et al: Avoiding invasive mechanical ventilation by extracorporeal carbon dioxide removal in patients failing noninvasive ventilation. Intensive Care Med 2012, 38(10):1632-1639.

doi:10.1186/2197-425X-3-S1-A512

Cite this article as: Harler et al: Coagulation disorders in subjects undergoing pump-driven veno-venous ECCO2-r for severe acute hypercapnic respiratory failure - a single center experience. Intensive Care Medicine Experimental 2015 3(Suppl 1):A512.

\section{Submit your manuscript to a SpringerOpen ${ }^{\circ}$ journal and benefit from:}

- Convenient online submission

- Rigorous peer review

- Immediate publication on acceptance

- Open access: articles freely available online

- High visibility within the field

- Retaining the copyright to your article 